\title{
Shoulder Joint
}

National Cancer Institute

\section{Source}

National Cancer Institute. Shoulder Joint. NCI Thesaurus. Code C33548.

A ball-and-socket joint at the upper end of the humerus, located at the junction of humerus and scapula. 